\title{
Immunocytochemistry and DNA-image cytometry in diagnostic effusion cytology. II. Diagnostic accuracy in equivocal smears
}

\author{
Helma Motherby ${ }^{\mathrm{a}, *}$, Nicolaus Friedrichs ${ }^{\mathrm{a}}$, \\ Mary Kube ${ }^{a}$, Bahram Nadjari ${ }^{\text {a }}$, \\ Kristiane Knops ${ }^{a}$, Andreas Donner ${ }^{b}$, \\ Betty Baschiera ${ }^{\mathrm{c}}$, Peter Dalquen ${ }^{\mathrm{c}}$ and \\ Alfred Böcking ${ }^{\mathrm{a}}$ \\ a Institute of Cytopathology, Heinrich Heine \\ University, Moorenstr. 5, D-40225 Düsseldorf, \\ Germany \\ ${ }^{\mathrm{b}}$ Institute of Pathology, Heinrich Heine University, \\ Moorenstr. 5, D-40225 Düsseldorf, Germany \\ ${ }^{\mathrm{c}}$ Division of Cytopathology, Institute of Pathology, \\ University Hospital Basel, Schönbeinstr. 40, \\ CH-4003 Basel, Switzerland
}

Received 18 February 1999

Accepted 10 June 1999

To determine sensitivity and specificity of different antibodies for the immunocytochemical detection of malignant cells in diagnostically equivocal effusions in comparison with those achieved by DNA-image cytometry.

65 cytologically doubtful effusions of the serous cavities were stained with twelve antibodies. Furthermore, DNAimage cytometry was performed. Data were correlated with patient follow-up.

Sensitivity of cellular staining of Ber-EP4 for the identification of malignant cells was $77.8 \%$, specificity of absent staining for benign cells was $100 \%$. Positive predictive value for the identification of malignant cells was $100 \%$, negative value $65.5 \%$. Sensitivity of DNA-aneuploidy for the identification of malignancy was $82.9 \%$, specificity of DNAnon-aneuploidy for benignity $94.7 \%$. The positive predictive value of DNA-aneuploidy for the occurrence of malignant cells was $96.7 \%$. Negative predictive value of DNAnon-aneuploidy was $72.0 \%$. Combining immunocytochemistry applying Ber-EP4 only and DNA-cytometry in equivocal effusions resulted in a sensitivity of $88.9 \%$ for the identifi-

\footnotetext{
${ }^{*}$ Correspondence to: Dr Helma Motherby. Tel.: +49 211 8118346; Fax: +49 2118118402 .
}

cation of malignant cells associated with a $95.0 \%$ specificity. Positive predictive value was $97.7 \%$, the negative one $79.2 \%$.

\section{Introduction}

Overall diagnostic accuracy of conventional effusion cytology on average is $80.5 \%$ [32] and $84.8 \%$ in our hands [27]. Diagnostic uncertainty also manifests in those effusions showing "equivocal" cells, as there are "inconclusive" cells or cells "suspicious for malignancy". According to Spriggs and Boddington (1989) [32] the rate of diagnostically doubtful effusions in routine cytology is about $6 \%$, in our institute it is currently $8 \%$. Improvement of diagnostic accuracy is therefore necessary in effusion cytology.

The diagnostic value of immunocytochemistry for the identification of malignant cells in effusions has often been emphasized [2,3,15,23,29,30]. An analysis of studies containing data on prevalence of cellular staining with different antibodies is given in Part I [28] of this study. As reported there Ber-EP4 is a highly sensitive $(95.4 \%)$ and $100 \%$ specific marker for the detection of (malignant) epithelial cells in effusions. For the differential diagnosis of carcinoma vs. mesothelioma anti-LeuM1 and -CEA were additionally recommended, resulting in a $98.0 \%$ correct immunocytochemical differentiation between both entities.

Only few authors have dealt with cytologically equivocal effusions in immunocytochemical studies [1, 4,9-12,18,19,22,24,31,33]. De Angelis [11] and Illingworth [18] have both shown a prevalence of cellular staining of Ber-EP4 in 33.3\% (1/3) of those patients which later proved to have a malignant disease of the serous membranes. The other authors examined different immunocytochemical markers, e.g., anti-CEA or -EMA. Although, these studies comprised only few cases (3-17, average 7.7), it can be concluded that cellular staining of Ber-EP4 is a sensitive marker for 
clarification of cytologically equivocal effusions. None of the cases definitely categorized as benign revealed staining for this marker in more than $5 \%$ of cells.

The diagnostic value of DNA-cytometry for the identification of malignant cells in effusions has been demonstrated by our group in two previous studies $[25,26]$. Prevalence of DNA-aneuploidy in malignant mesotheliomas was $83 \%$ and $100 \%$ in carcinomas metastatic to the serous membranes, whereas none of the reactive effusions revealed DNA-aneuploidy.

Only few authors have also dealt with cytologically equivocal effusions in DNA-cytometric studies. They have shown a prevalence of DNA-aneuploidy in 12.5$60 \%[9,13,14,17,20,24]$ of those patients which later proved to have a malignant disease of the serous membranes. It can be concluded that DNA-aneuploidy is a sensitive marker for the identification of neoplastic cells. None of the cases definitely categorized as benign revealed DNA-aneuploidy. We also have previously proven the value of DNA-aneuploidy to detect malignant cells in equivocal effusions [26]. The sensitivity of DNA-aneuploidy for the identification of malignancy was $55.9 \%$, specificity of DNA-nonaneuploidy for benignity was $94.1 \%$.

After we have reported on the prevalence of 12 different antibodies in various types of benign and malignant cells in effusions with and without tumour cells (carcinomatoses and mesotheliomas) (Part 1 of this study) [28] the aim of the present study was to investigate the ability of the most sensitive and specific immunologic markers to identify malignant cells in diagnostically equivocal effusions. Furthermore, sensitivity and specificity of DNA-aneuploidy, which had been proven to be an excellent marker for neoplastic cells in effusions in our previous studies [25,26,28] was investigated on the same specimens.

Different to other investigations, this study was especially dedicated to the combined use of both adjuvant methods in a large group of cytologically equivocal effusions ( $n=65$ ) including detailed follow-up of all patients. It was performed prospectively, which means that diagnoses as evaluated here were immediately reported to the clinicians. Thus our diagnostic routine performance was analyzed. Follow-up of patients validated the diagnoses obtained by application of the two adjuvant methods.

\section{Materials and methods}

\subsection{Specimens and patient population}

Subject of our study were 65 effusions of the serous cavities with cytologically equivocal diagnosis (52 pleural, 11 peritoneal and 2 pericardial) routinely investigated between April 1996 and December 1997 in the Institute of Cytopathology. The patients were from the University Hospital of Düsseldorf as well as from hospitals of the surrounding area. 65 equivocal effusions contained atypical mesothelial or epithelial cells suitable for application of adjuvant methods. A minimum of 30 reference and about 50 analysis cells were necessary for DNA-image cytometry, whereas several strongly stained cells $(n>5)$ per slide were considered as sufficient for immunocytochemistry. Both immunocytochemistry and DNA-cytometry were applied on 53 effusions, the first method only on eleven, the latter only on one additional case. Four effusions occurring during the above mentioned period were not included in the study because of cellular overlap not suitable for DNA-cytometry as well as absence of atypical cells on those slides prepared for immunocytochemistry.

\subsection{Staining of specimens}

Details of the procedure were described in our previous papers $[25,28]$. In brief, for purposes of routine cytological diagnosis three slides were air-dried and stained according to May-Grünwald-Giemsa. For measurement of DNA content one of these was later uncovered in xylene and subsequently Feulgen-stained in a temperature-controlled staining machine with Schiff's reagent according to the protocol applied in our previous papers $[6,7,25,28]$. Five further slides were immediately fixed in a modification of Delaunay's solution and stained according to Papanicolaou [28]. They were used for immunocytochemistry after uncovering in xylene.

\subsection{Cytological diagnosis}

The specimens were evaluated according to generally accepted diagnostic criteria [2,5,21] described in our previous papers [27]. All specimens contained cytologically equivocal cells. $23(35.4 \%)$ of the cases were diagnosed as "doubtful" and $42(64.6 \%)$ as "suspicious for malignancy". Effusions diagnosed as "doubtful" revealed atypical cellular degeneration or activation. In those diagnosed as "suspicious for malignancy" only sparse abnormal cells were seen or diagnostic criteria of malignancy were not sufficiently expressed [8]. 


\subsection{Immunocytochemistry: staining and evaluation}

Detailed staining protocols (as well as specifications of antibodies applied) are described in our previous paper [28]. In brief, the immunological detection method applied was the Avidin-Biotin-Complex method (ABC). Incubations were carried out with a primary antibody (Ber-EP4, anti-B72.3, -CA 125, -CEA, -Desmin, -EMA, -HBME-1, -LeuM1, -Lu5, -MAC 387, -MNF 116 and Vimentin), followed by a biotinylated link antibody, then the ABC-EliteStandard. The substrate-chromagen-reagent was AEC (3-amino-9-ethylcarbazole).

The number of primary antibodies applied depended on the quantity of atypical cells present on the slides. Up to twelve antibodies were used. If necessary slides were separated in up to three regions using a Dakopen (Dako, Glostrup, Denmark). At least five cells per antibody were requested in one slide region. Ber-EP4 was applied only ( $n=2$ cases) if merely few atypical cells $(>5)$ were present. Ber-EP4 was combined with -EMA and -CEA ( $n=8$ cases) or additionally with -LeuM1 ( $n=42$ cases) if several atypical cells ( $>10$, mostly $30-50)$ were found. Five ( $n=4$ cases), six $(n=1$ case), nine ( $n=1$ case), ten ( $n=2$ cases), eleven ( $n=1$ case) and twelve ( $n=3$ cases $)$ antibodies were applied if many cells $(>50)$ were seen.

Slides were evaluated applying a semiquantitative score: “-” (negative): no cellular staining detectable. " $(+)$ " (negative): less than $5 \%$ of the respective cell population weakly stained. "+" (positive): 6-30\% of the respective cell population stained, " ++ " (positive): $31-70 \%$ of the respective cell population stained and " +++ " (positive): $71-100 \%$ of the respective cell population stained.

\subsection{DNA-cytometry: measurement and evaluation}

Measurements of nuclear DNA were performed as described in our previous papers $[6,7,25,28]$. In brief, 30 lymphocytes were measured as reference cells, meeting a coefficient of variation $<5 \%$. The coefficient of correlation between nuclear area and integrated optical density (IOD) of reference cells was $r<0.4$. Subsequently, if present 300 atypical cells were measured per specimen interactively at random. Otherwise, only those few cells were measured which were available: Two specimens revealed less than 50 cells, five 51100 cells, eleven 101-150, six 151-200, twelve 201250, ten 251-300 and eight more than 300 measurable cells. The ZEISS CYRES workstation (Zeiss, Jena,
Germany) was used for measurements (Part I) [28]. The performance of the system meets the standards of the updated consensus report of the ESACP task force on standardization of diagnostic DNA-image cytometry $[7,16]$. The data were diagnostically interpreted as described in our previous paper [25]. DNA-aneuploidy was assumed, if an abnormal DNA-stemline (STL) (DNA-index of the stemline was $<0.90>1.10$ or $<1.80>2.20$ or $<3.60>4.40$ ) and/or the coefficient of variation $(\mathrm{CV})$ of the first DNA-stemline was $\geqslant 10 \%$ and/or cells $>9 \mathrm{c}$ occurred (9c exceeding events (9c EE)).

\subsection{Validation of cytologic diagnosis}

According to patient follow-up (periods of 6-18 months) the investigated materials from the serous membranes were classified as either containing malignant cells or not. We accepted patient histories as presenting sufficient evidence for the presence or absence of tumour cells in effusions. These revealed either histologic follow-up of a tumour of the serous membrane itself $(9 / 65=13.8 \%)$ or of the respective primary tumour $(35 / 65=53.8 \%)$. Furthermore, clinical evidence for a malignant nature of the effusion was considered valid, applying such advanced diagnostic techniques as radiology, computer tomography $(21 / 65=32.3 \%)$. Patients presenting abnormal cells in effusions revealed the following primary tumours: carcinomas of the breast (12), the ovary (3), the thyroid (1), the lung (7), the esophagus (1), the stomach (4), the pancreas (4), the kidney (1), the urothelium (2), as well as carcinomas of unknown primary (7). Furthermore, malignant melanoma (1) and malignant mesotheliomas (3) occurred. Non-malignant cases showed the following basic diseases: pneumonia (12), congestive heart failure (6) and cirrhosis of the liver (1).

\section{Results}

In this part, as well as in the first part of this study [28], Ber-EP4, anti-LeuM1, -EMA and-CEA were the immunocytochemical markers with the most distinct results concerning the identification of malignant epithelial cells and their differentiation from those of mesotheliomas.

Prevalence of cellular staining of Ber-EP4 was $54.7 \%$, sensitivity for its ability to identify malignancy was $77.8 \%$, specificity of absence of cellular staining for prospective benignity was $100 \%$ (Fig. 1, Table 1). 


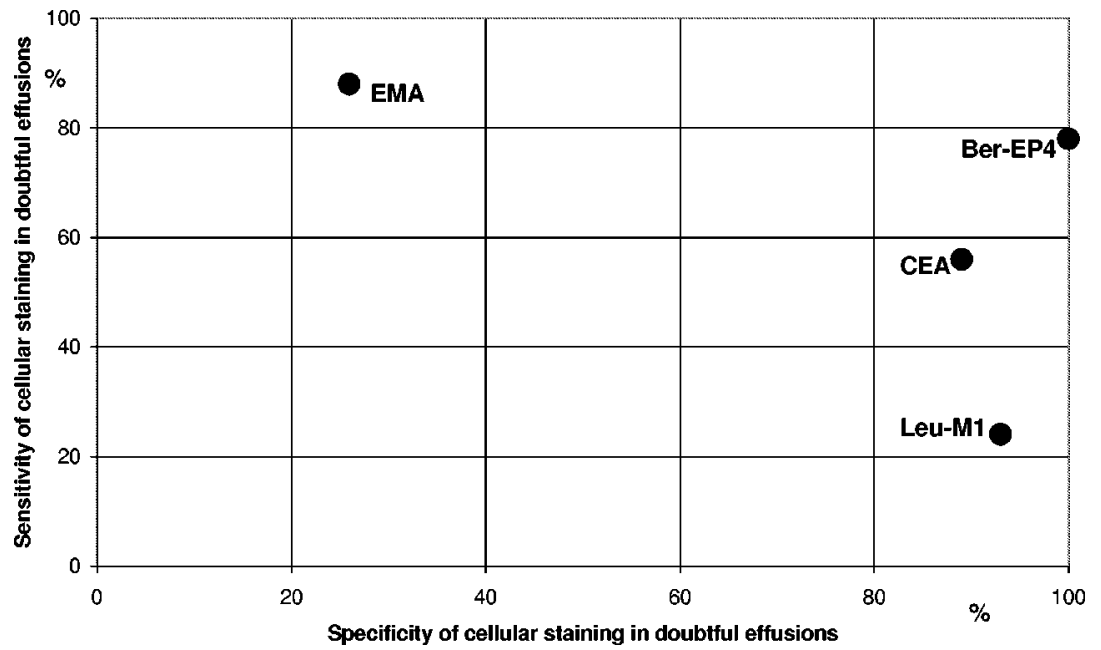

Fig. 1. Sensitivity and specificity of cellular staining by four immunocytochemical markers in 65 equivocal effusions. Ber-EP4 marks a surface and cytoplasmic glycoprotein, EMA (epithelial membrane antigen) a human milk fat globulin, CEA (carcinoembryonic antigen) a heavily glycosilated cytoplasmic protein and Leu-M1 a cytoplasmic oligosaccharid.

Table 1

Results of immunocytochemistry in equivocal effusions

\begin{tabular}{lcccc}
\hline & \multicolumn{4}{c}{ Antibody applied } \\
\cline { 2 - 5 } & Ber-EP4 & Leu-M1 & EMA & CEA \\
\hline Prevalence & $54.7 \%$ & $19.2 \%$ & $83.6 \%$ & $42.2 \%$ \\
& $(35 / 64)$ & $(10 / 52)$ & $(51 / 61)$ & $(27 / 64)$ \\
Sensitivity & $77.8 \%$ & $24.3 \%$ & $88.1 \%$ & $55.6 \%$ \\
& $(35 / 45)$ & $(9 / 37)$ & $(37 / 42)$ & $(25 / 45)$ \\
Specifity & $100.0 \%$ & $93.3 \%$ & $26.3 \%$ & $89.5 \%$ \\
& $(19 / 19)$ & $(14 / 15)$ & $(5 / 19)$ & $(17 / 19)$ \\
Positive predictive value & $100.0 \%$ & $90.0 \%$ & $72.5 \%$ & $92.6 \%$ \\
& $(35 / 35)$ & $(9 / 10)$ & $(37 / 51)$ & $(25 / 27)$ \\
Negative predictive value & $65.5 \%$ & $33.3 \%$ & $50.0 \%$ & $45.9 \%$ \\
& $(19 / 29)$ & $(14 / 42)$ & $(5 / 10)$ & $(17 / 37)$ \\
\hline
\end{tabular}

Positive predictive value of cellular staining of BerEP4 for the identification of neoplastic cells was $100 \%$ and negative predictive value of absent staining for the absence of neoplastic cells $65.5 \%$ (Table 1 ).

Prevalences of cellular staining for LeuM1, EMA and CEA were 19.9, 83.6 and $42.2 \%$, respectively. Sensitivities of these markers were $24.3,88.1$ and $55.6 \%$, while specificities were 93.3, 26.3 and $89.5 \%$, respectively (Fig. 1, Table 1). Positive predictive values were 90, 72.5 and $92.6 \%$, negative ones were 33.3, 50.0 and $45.9 \%$ respectively (Table 1 ). The other antibodies applied were not of additional help in these aspects.

As for DNA-image cytometry 29/54 of the diagnostically equivocal effusions were DNA-aneuploid (Table 2). This corresponds to a prevalence of DNAaneuploidy in equivocal cells in effusions of $53.7 \%$.
Table 2

Prevalence of DNA-aneuploidy in cells in cytologically equivocal effusions

\begin{tabular}{lc}
\hline DNA-ploidy status & $n=54(100 \%)$ \\
\hline DNA-non-aneuploid & $25(46.3 \%)$ \\
DNA-aneuploid & $29(53.7 \%)$ \\
\hline
\end{tabular}

The detection rate of DNA-aneuploidy depends on the application of the type and number of different algorithms. An abnormal stemline $(22 / 54=40.7 \%)$ as well as $9 \mathrm{c} \operatorname{EE}(22 / 54=40.7 \%)$ were the most frequent aspects of DNA-aneuploidy followed by a $\mathrm{CV}$ of the first stemline $\geqslant 10 \%(6 / 54=11.1 \%)$. The combined application of the first two algorithms significantly increased the rate of detection of DNAaneuploidy to $53.7 \%$ (29/54). Additionally applying 
Table 3

Immunocytochemistry and DNA-image-cytometry in equivocal effusions

\begin{tabular}{lccc}
\hline & $\begin{array}{c}\text { Immunocytochemistry } \\
\text { (Ber Ep4) }\end{array}$ & $\begin{array}{c}\text { DNA-image cytometry } \\
\text { (DNA-aneuploid) }\end{array}$ & $\begin{array}{c}\text { Immunocytochemistry } \\
\text { and/or DNA-image- } \\
\text { cytometry }\end{array}$ \\
\hline Prevalence & $54.7 \%(35 / 64)$ & $53.7 \%(29 / 54)$ & $67.7 \%(44 / 65)$ \\
Sensitivity & $77.8 \%(35 / 45)$ & $82.9 \%(29 / 35)$ & $88.9 \%(40 / 45)$ \\
Specifity & $100.0 \%(20 / 20)$ & $94.7 \%(18 / 19)$ & $95.0 \%(19 / 20)$ \\
Positive predictive value & $100.0 \%(35 / 35)$ & $96.7 \%(29 / 30)$ & $97.7 \%(43 / 44)$ \\
Negative predictive value & $65.5 \%(19 / 29)$ & $72.0 \%(18 / 25)$ & $79.2 \%(19 / 24)$ \\
\hline
\end{tabular}

the $\mathrm{CV}$ of the first stemline as a further criterion of DNA-aneuploidy did not increase its rate of identification. One of the non-malignant cases according to the patients follow-up showed an abnormal DNA-stemline at $1.7 \mathrm{c}$.

Sensitivity of DNA-aneuploidy (abnormal STL plus $9 \mathrm{c}$ EE) or identification of malignant cells in equivocal effusions was $82.9 \%$, specificity of DNA-nonaneuploidy for benign cells was $94.7 \%$.

The positive predictive value of the marker DNAaneuploidy in equivocal effusions was $96.7 \%$, since all but one DNA-aneuploid case showed malignancy in the follow-up. The negative predictive value of DNAnon-aneuploidy was $72.0 \%$.

Combining both methods in the diagnosis of equivocal effusions (Table 3) leads to an increase of sensitivity from $77.8 \%$ applying immunocytochemistry (BerEP4 alone) and $82.9 \%$ applying DNA-cytometry (aneuploidy) to $88.9 \%$ applying both methods. Specificity of absence of Ber-EP4 staining for prospective benignity is $100 \%$ and for absence of DNA-aneuploidy $94.7 \%$, respectively, and $95.0 \%$ for combining both methods. Positive predictive value of cellular staining for the identification of neoplastic cells is $100 \%$ for immunocytochemistry alone, $96.7 \%$ for DNA-cytometry, respectively, and $97.7 \%$ for the combination. Negative predictive value for the absence of neoplastic cells increases from $65.5 \%$ for immunocytochemistry alone and $72.0 \%$ for DNA-cytometry alone respectively to $79.2 \%$ by the combination of both methods.

Combining data of Part I of this study [28] on prevalence of immunocytochemical markers (Ber-EP4 alone) and DNA-aneuploidy in tumour cell positive and negative effusions with data of this second part in equivocal effusions the overall sensitivity of both methods in effusions is $96.6 \%$, specificity $98.6 \%$, positive predictive value $99.3 \%$ and the negative one 93.4\%. Overall diagnostic accuracy $(n=$ correctly positive + correctly negative / total no. cases) is $97.2 \%$

\section{Discussion}

In Part I of our study [28] we proposed that the identification of Ber-EP4 positive cells and/or DNAaneuploidy in cytologically equivocal effusions [26] may be used as a highly specific and sufficiently sensitive marker for neoplastic cells. In this second part we investigated this hypothesis on 65 cytologically equivocal effusions.

Combining results of both parts of this study we were able to demonstrate an overall sensitivity of combined application of both methods in this selected group of effusions to be $96.6 \%$. Specificity was $98.6 \%$, positive predictive value $99.3 \%$, the negative one $93.4 \%$, and the overall diagnostic accuracy was $97.2 \%$.

Other authors have proven the diagnostic usefulness of cellular staining for Ber-EP4 for the identification of malignant cells in effusions. Yet, only few of them have dealt explicitly with cytologically equivocal effusions in immunocytochemical studies [1,4,9-12,18, 19,22,24,31,33]. De Angelis [11] and Illingworth [18] have both shown a prevalence of cellular staining for Ber-EP4 in $33.3 \%$ in patients in whom the follow-up had proven a malignant disease as cause of the effusion. The other authors examined staining of other immunocytochemical markers, e.g., anti-CEA or -EMA. While all of these authors investigated prevalences of cellular staining for the applied antibodies, only two of them (Illingworth et al. [18]: $n=2$ equivocal/59 total effusions; and Matter-Walstra and Kraft [24]: $n=33$ equivocal/75 total effusions) drew conclusions concerning the resulting sensitivities and specificities, positive and negative predictive values. The fact that only two authors calculated these data may be due to the limited number of cases of equivocal effusions (average 7.7 cases) included in these studies, not allowing calculation of these data.

The high prevalence of cellular staining for Ber-EP4 found in this study may also be due to our staining pro- 
tocol. We suggest to apply immunocytochemical methods only according to standardized protocols adapted to effusion specimens, e.g., fixation in Delaunay's solution and with optimized antibody dilutions. A further important aspect, as discussed in Part I, concerns the interpretation of immunocytochemical staining in effusions. For the tumour cell positive effusions reported there we suggested a cut-off level for positive staining $>5 \%$ of cells from one type (e.g., mesothelial) in order to avoid false positive results due to unspecific staining. The interpretation of staining results of equivocal effusions concerning the percentage of atypical cells stained seems to be more difficult. There may be only few atypical cells on the slide, but these may reflect a high percentage of positive cells. A cut-off level for positive staining at $>5 \%$ does not make sense here, as even few stained cells may be interpreted as positive. But, in comparison to negative effusions, where few weakly stained cells might be found, these should be strongly positive.

As in our previous study, we conclude that the application of Ber-EP4 only, as opposed to a panel of antibodies, results in an excellent detection rate of malignant cells.

Other authors have already proven the diagnostic usefulness of DNA-aneuploidy as a marker for malignancy in effusions as well by image- as by flow-cytometry. Yet, few authors have dealt explicitly with cytologically equivocal effusions in DNAcytometric studies. They have shown prevalences of DNA-aneuploidy in 12,5\% [17], 37.5\% [9], 42.4\% [24], 50\% [14,20] and 60\% [13] in patients in whom the follow-up had proven a malignant disease as cause of the effusion.

As previously discussed in detail $[25,26]$ most of these authors used DNA-stemline aneuploidy as the only criterion for diagnostic interpretation. We propose the combined use of three different algorithms for the identification of DNA-aneuploidy [25,26]: position of any DNA-stemline, the occurrence of cells $>9 \mathrm{c}$ and $\mathrm{CV}$ of the first stemline $\geqslant 10 \%$.

We recommend the strict consideration of the updated standards of the European Society for Analytical Cellular Pathology (ESACP) for diagnostic DNAimage-cytometry $[7,16]$ otherwise false positive and false negative diagnoses may occur.

While other authors merely investigated prevalence of DNA-aneuploidy, we were now able to present sensitivities, specificities, positive and negative predictive values.

Apart from our study three other authors have suggested the combined use of immunocytochemi- cal markers and DNA-cytometry. Croonen et al. [9] and Joseph et al. [20] applied DNA-flow cytometry. Matter-Walstra and Kraft [24] introduced the combined use of staining for Ber-EP4 and DNA-image cytometry, but they applied different algorithms for identification of DNA-aneuploidy [25,26]. None of these authors included equivocal effusions in their studies.

At present there is no general agreement as to the "golden standard" for evaluation of the diagnostic accuracy of immunocytochemical or DNA-cytometric diagnoses in effusions [28]. In our study the immunological finding of Ber-EP4 positive cellular staining or the cytometric finding of DNA-aneuploidy was classified as correctly positive if patient follow-up revealed histologic or clinical evidence for a malignant nature of the effusion. Thus, only one false positive DNAcytometric result was observed. It must be considered that this case might be correctly positive, but that the tumour had not yet been found (e.g., carcinoma of unknown primary (CUP)). The immunocytochemical absence of Ber-EP4 staining or the DNA-cytometric finding of DNA-non-aneuploidy was classified as correctly negative if the patient follow-up revealed histologic or clinical evidence for a benign nature of the effusion.

This investigation was dedicated to the use of both methods in a relatively large group of patients revealing cytologically equivocal effusions $(n=65)$ including detailed follow-up. It was performed prospectively, which means that our routine diagnostic performance was analyzed. Diagnoses as evaluated here were reported to the clinicians within one week after receiving the specimens. Follow-up of patients validated the diagnosis obtained by application of adjuvant methods.

We investigated the combined use of immunocytochemistry applying Ber-EP4 and DNA-image cytometry searching for DNA-aneuploidy as markers for neoplasia. The first method revealed a sensitivity to detect malignant cells in cytologically equivocal effusions of $77.8 \%$, the latter of $82.9 \%$. It must be considered that the sensitivity of immunocytochemistry is lower than of DNA-cytometry due to the processing of slides in Delaunay's fixation for immunocytochemistry with the risk of loosing tumour cells as opposed to air-drying of slides for DNA-cytometry. By combining both adjuvant methods a sensitivity of $88.9 \%$ was achieved.

The rate of cytologically equivocal effusions was decreased by adjuvant methods from currently 8 to $0 \%$ as all cases were finally decided to be either tumour cell positive or negative. Evaluating our diagnoses we realized that in five cases definitely diagnosed as tumour cell negative due to absence of immunocytochemical 
staining or of DNA-aneuploidy we made false negative diagnoses as the patients nevertheless revealed a malignant disease and on second look their smears still revealed cells "suspicious for malignancy" in their effusions. It must be concluded that negative results in the adjuvant methods applied did not exclude neoplasia.

Nevertheless, immunocytochemistry (Ber-EP4 positive staining) and DNA-image-cytometry (DNA-aneuploidy) applied to effusions of all 218 patients evaluated in both parts of this study were able to increase the overall diagnostic accuracy from 70.6 to $97.2 \%$.

As both methods revealed high sensitivities it is difficult to decide which one should be preferred in a routine laboratory. The decision may depend on the preexisting equipment, the skills of the personnel and the expected costs (investments in machinery). It may also depend on the possible application of either method to other specimens and diagnostic questions (e.g., immunocytochemistry for the classification of fine-needle aspiration biopsies or DNA-cytometry for grading tumour malignancies). Immunocytochemistry is easy to perform but it requires special fixation. DNA-image cytometry may be more time consuming and needs cytological expertise. Its advantage is that it may be performed retrospectively, irrespective of the type of preceding fixation and staining and even on archived slides. The combined application of both methods anyway results in an increase of security of diagnostic decisions. The individual pathologist will achieve best results with that adjuvant method he feels familiar with.

We recommend to apply both adjuvant methods on all effusions yielding cytologically equivocal or doubtful diagnoses. Thus overall diagnostic accuracy of effusion cytology in a routine laboratory may be improved significantly.

\section{Acknowledgements}

We wish to thank all clinicians who generously supported us by providing patient follow-up data. Furthermore, we would like to express our thanks to Mrs B. Buckstegge and Mrs H. Müschenborn for excellent preparation of slides and to Mrs D. Shittu for expert typing of the manuscript.

\section{References}

[1] A. Al-Nafusi and P.J. Carder, Monoclonal antibodies in the cytodiagnosis of serous effusions, Cytopathology 1 (1990), 119128.
[2] C.W.M. Bedrossian, Malignant Effusions. A Multimodal Approach to Cytologic Diagnosis, Igaku-Shoin Medical Publishers, New York, Tokyo, 1994.

[3] C.W.M. Bedrossian, Diagnostic problems in serous effusions, Diagn. Cytopathol. 19(2) (1998), 131-137.

[4] M. Beuzlin-Yvraut, A. Bourguignat, E. Phillips, A. Roseto and E. Osinaga, Immunocytological analysis of the Tn associated antigen $83 \mathrm{D}_{4}$ in serous effusions from patients with cancer: Comparison with Tn soluble glycoprotein, J. Clin. Pathol. 48 (1995), 433-437.

[5] M. Bibbo, Comprehensive Cytopathology, W.B. Saunders Company, Philadelphia, 1991, pp. 541-614.

[6] A. Böcking, DNA measurements. When and why?, in: Compendium on Quality Assurance, Proficiency Testing and Workload Limitations, G.L. Wied, C.M. Keebler, D.L. Rosenthal, U. Schenck, T.M. Somrak and G.P. Vooijs, eds, Tutorials of Cytology, Chicago, IL, USA, 1995, pp. 170-188.

[7] A. Böcking, F. Giroud and A. Reith, Consensus report of the European Society for Analytical Cellular Pathology task force on standardization of diagnostic DNA image cytometry, Analyt. Cell. Path. 8 (1995), 67-74.

[8] A. Böcking and N. Freudenberg, Standardisierte Befunderstellung in der extragenitalen Zytologie, Der Pathologe 19 (1998), 235-258.

[9] A.M. Croonen, P. van der Valk, C.J. Herman and J. Lindeman, Cytology, immunopathology and flow cytometry in the diagnosis of pleural and peritoneal effusions, Lab. Invest. 58(6) (1988), 725-732.

[10] G. Daste, G. Serre, M.A. Mauduyt, C. Vincent, P. Caveriviere and J.P. Soleilhavoup, Immunophenotyping of mesothelial cells and carcinoma cells with monoclonal antibodies to cytokeratins, vimentin, CEA and EMA improves the cytodiagnosis of serous effusions, Cytopathology 2 (1991), 19-28.

[11] M. De Angelis, I.D. Buley, A. Heryet and W. Gray, Immunocytochemical staining of serous effusions with the monoclonal antibody Ber-EP4, Cytopathology 3 (1992), 111-117.

[12] J.M. Esteban, S. Yokota, S. Husain and H. Battifora, Immunocytochemical profile of benign and carcinomatous effusions, Am. J. Clin. Pathol. 94(6) (1990), 698-705.

[13] D.F. Fischler, S. Wongbunnate, D.A. Johnston and R.L. Katz, DNA content by image analysis. An accurate discriminator of malignancy in pericardial effusions, Analyt. Quant. Cytol. Histol. 16(3) (1994), 167-173.

[14] S.C. Freni, J. James and F.J.A. Prop, Tumor diagnosis in pleural and ascitic effusions based on DNA cytophotometry, Acta Cytol. 15(2) (1971), 154-162.

[15] J. Guzman, Immunocytochemistry: when and why?, in: Compendium on the Quality Assurance, Proficiency Testing and Workload limitations in Clinical Cytology, G.L. Wied, C.M. Keebler, D.L. Rosenthal, U. Schenck, T.M. Somrak and G.P. Vooijs, eds, Tutorials of Cytology, Chicago, 1995, pp. 197-201.

[16] G. Haroske, F. Giroud, A. Reith and A. Böcking, Updated European Society for Analytical Cellular Pathology consensus report on diagnostic DNA image cytometry, Analyt. Cell. Path. (1998), accepted for publication.

[17] D.W. Hedley, J. Philips, C.A. Rugg and I.W. Taylor, Measurement of DNA content as an adjunct to diagnostic cytology in malignant effusions, Eur. J. Cancer. Clin. Oncol. 20(6) (1984), 749-752. 
[18] A.L. Illingworth, J.A. Young and G.D. Johnson, Immunofluorescent staining of metastatic carcinoma cells in serous fluid with carcinoembryonic antibody, epithelial membrane antibody, AUA-1 and Ber-EP4, Cytopathology 5 (1994), 270-281.

[19] W.W. Johnston, C.A. Szpak, S.C. Lottich, A. Thor and J. Schlom, Use of a monoclonal antibody (B72.3) as an immunocytochemical adjunct to diagnosis of adenocarcinoma in human effusions, Cancer Res. 45 (1985), 1894-1900.

[20] M.G. Joseph, D. Banerjee, P. Harris, S. Gibson and R.G. McFadden, Multiparameter flow cytometric DNA analysis of effusions: a prospective study of 36 cases compared with routine cytology and immunohistochemistry, Mod. Path. 8(6) (1995), 686-693.

[21] L.G. Koss, Diagnostic Cytology and its Histopathologic Bases, 4th edn, J.B. Lippincott Company, Philadelphia, 1992.

[22] S.J. Lee, J.H. Nam, M.C. Lee, C.S. Park and S.W. Juhng, Immunohistochemical panel for distinguishing between carcinoma and reactive mesothelial cells in serous effusions, Acta Cytol. 40 (1995), 631-636.

[23] M.R. Mason, C. Bedrossian and C.A. Fahey, Value of immunocytochemistry in the study of malignant effusions, Diagn. Cytopathol. 3 (1987), 215-221.

[24] K.W. Matter-Walstra and R. Kraft, Atypical cells in effusions: diagnostic value of cell image analysis combined with immunocytochemistry, Diagn. Cytopathol. 15(4) (1996), 263269.

[25] H. Motherby, T. Marcy, M. Hecker et al., Static DNAcytometry as a diagnostic aid in effusion cytology. I. DNA aneuploidy for identification and differentiation of primary and secondary tumours of the serous membranes, Analyt. Quant. Cytol. Histol. 20(3) (1998), 153-161.

[26] H. Motherby, B. Nadjari, T. Remmerbach et al., Static DNA cytometry as a diagnostic aid in effusion cytology. II. DNA ane- uploidy for identification of neoplastic cells in equivocal effusions, Analyt. Quant. Cytol. Histol. 20(3) (1998), 162-168.

[27] H. Motherby, B. Nadjari, P. Friegel, J. Kohaus, U. Ramp and A. Böcking, Diagnostic accuracy of effusion cytology, Diagn. Cytol. 20(6) (1999), 350-357.

[28] H. Motherby, M. Kube, N. Friedrichs et al., Immunocytochemistry and DNA-image cytometry in diagnostic effusion cytology. I. Prevalence of markers in tumour cell positive and negative smears, Anal. Cell. Pathol. (1999), submitted for publication.

[29] P.W. Shield, J.J. Callan and P.L. Devine, Markers for metastatic adenocarcinoma in serous effusion specimens, Diagn. Cytopathol. 11 (1994), 237-245.

[30] J.F. Silverman, K. Nance, B. Phillips and H.A.T. Norris, The use of immunoperoxidase panels for the cytologic diagnosis of malignancy in serous effusions, Diagn. Cytopathol. 3 (1987), 134-140.

[31] S. Singer, M.M. Boddington and E.A. Hudson, Immunocytochemical reaction of $\mathrm{Ca} 1$ and HMFG2 monoclonal antibodies with cells from serous effusions, J. Clin. Pathol. 38 (1985), 180-184.

[32] A.I. Spriggs and M.M. Boddington, Atlas of serous fluid cytopathology. A guide to the cells of pleural, pericardial, peritoneal and hydrocele fluids, in: Current Histopathology Series, Vol. 14, G.A. Gresham, ed., Kluwer Academic Publishers, Dordrecht, 1989.

[33] D.G. Tiniakos, R.M. Healicon, T. Hair, V. Wadehra, C.H.W. Horne and B. Angus, P53 immunostaining as a marker of malignancy in cytologic preparations of body fluids, Acta Cytol. 39 (1995), 171-176. 


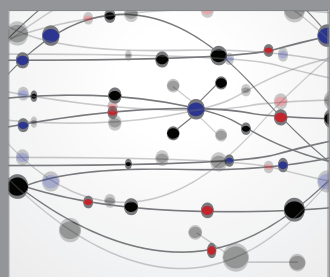

The Scientific World Journal
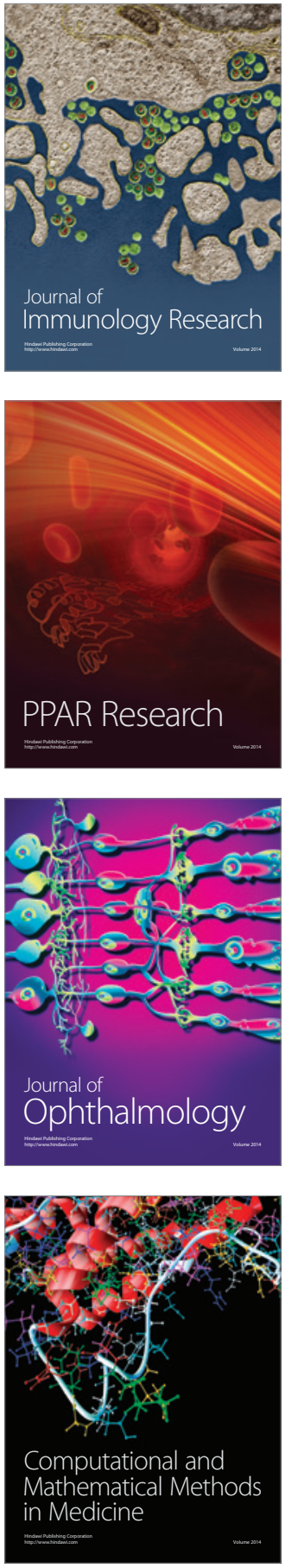

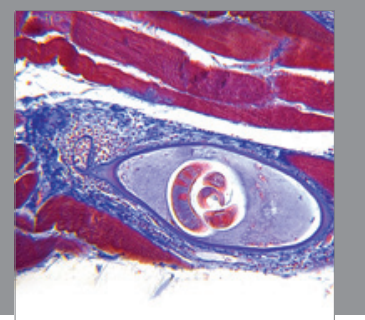

Gastroenterology

Research and Practice
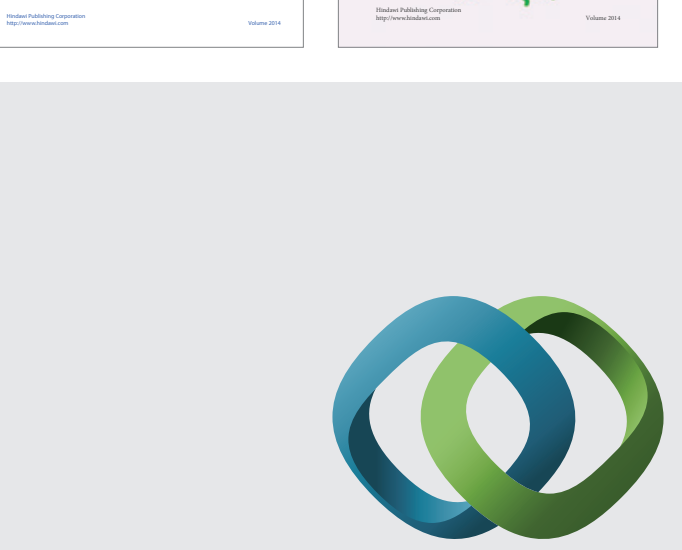

\section{Hindawi}

Submit your manuscripts at

http://www.hindawi.com
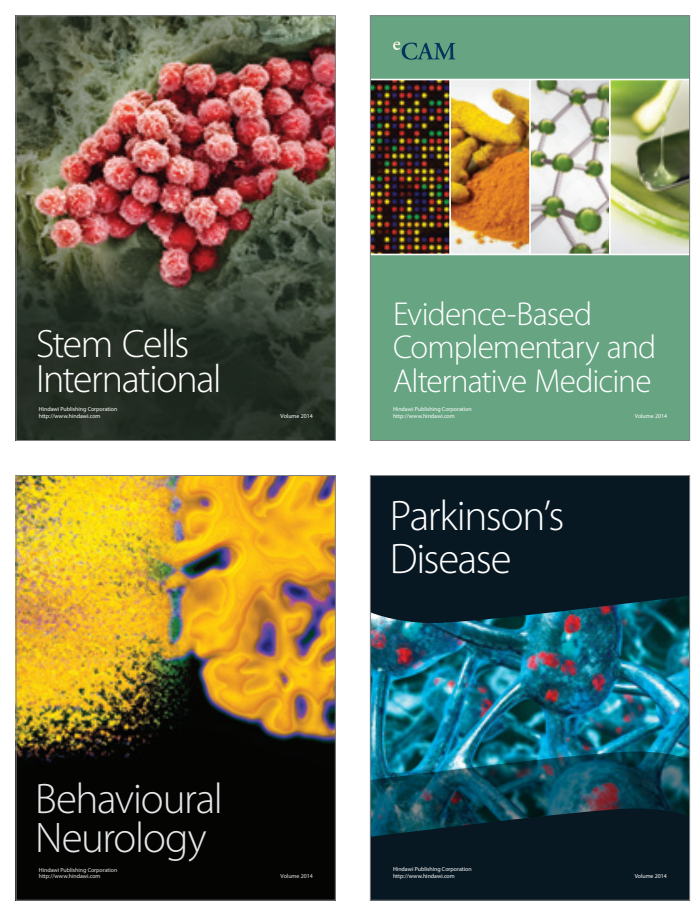

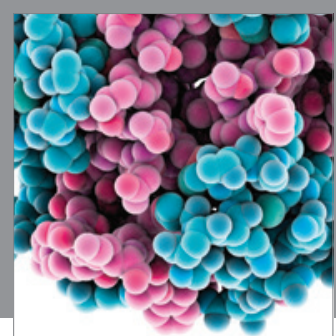

Journal of
Diabetes Research

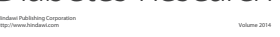

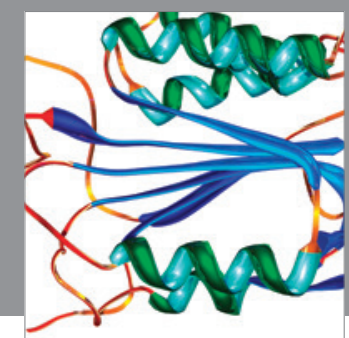

Disease Markers
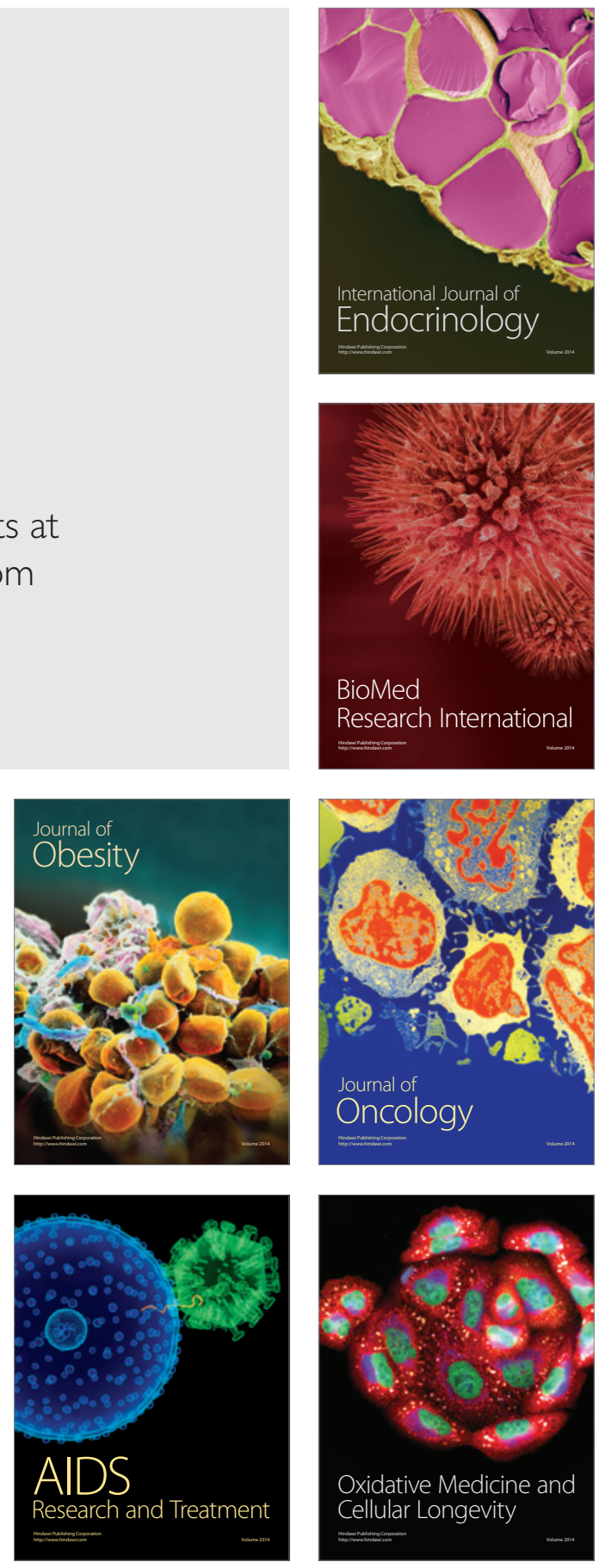